\title{
Determination of the Prevalence of the Common Dermatological Conditions in Elderly Population Attending a Tertiary Care Hospital
}

\author{
Md. Saidur Rahman*1, Md. Abdul Mannan², Md. Anower Hossain ${ }^{3}$, \\ Md. Tozammel Hoque ${ }^{4}$, A K M Ahsan Habib
}

\section{Abstract}

Introduction: Skin disorders are common in elderly people. Systemic diseases promote the development of dermatological conditions. Various systemic diseases contribute to the presence of cutaneous disorders, indicating the possibility that a skin abnormality may sometimes be the first and only symptom of a much more serious medical problem. The aim of the study to determine the frequency of skin diseases in elderly patients. Materials \& Methods: This was a cross-sectional study and non-probability convenient sampling technique was used. Patients were recruited from attending the Dermatology Out-patient Department of SZMCH during the study from January'2018 to July'2018. Patients included in the study having skin diseases aged between 60-80 years, including all those who were diabetic and hypertensive because diabetes and hypertension are the most common comorbid conditions among these elderly patients. Patients were included having skin diseases including pruritus, dermatitis, xerosis, eczema, psoriasis, scabies, bacterial infection, and fungal infections. Results: More than half (53.0\%) patients belonged to age 71-80 years. Three fourth (75.0\%) patients had pruritus followed by 37(37.0\%) had dermatitis, 24(24.0\%) had xerosis, 23(23.0\%) had eczema and $12(12.0 \%)$ had bacterial infections. Pruritis, dermatitis, eczema and bacterial infections were statistically significant $(p<0.05)$ among three groups. Conclusion: More than half of the patients belonged to age more than 70 years of age. Most common (three fourth) skin patients had pruritis, followed by more common skin patients were found dermatitis, xerosis, eczema and bacterial infection. Pruritis, dermatitis, eczema and bacterial infections were statistically significant in different age groups.

Keywords: Dermatological conditions, Elderly population, Tertiary care hospital.

Number of Tables: 03; Number of References: 12; Number of Correspondences: 05

*1. Corresponding Author:

Dr. Md. Saidur Rahman

Associate Professor

Department of Dermatology and Venereology

Shaheed Ziaur Rahman Medical College, Bogura.

Email: saidur_hivaids@yahoo.com

Mobile: 01715805050

2. Dr. Md. Abdul Mannan

Associate Professor

Department of Dermatology and Venereology

Shaheed Ziaur Rahman Medical College, Bogura.

3. Dr. (Maj.) Md. Anower Hossain (Rtd.)

Associate Professor

Department of Dermatology and Venereology

Ibn Sina Medical College, Dhaka.

4. Dr. Md. Tozammel Hoque

Junior Consultant

Department of Medicine

Adhunik Sadar Hospital, Thakurgaon.

5. Dr. A K M Ahsan Habib

Professor

Department of Community Medicine

Shaheed Ziaur Rahman Medical College, Bogura.

\section{Introduction}

Skin disorders are common in elderly people. Systemic diseases promote the development of dermatological conditions ${ }^{1}$. Aging is a permanent and active process which affects all organs of the body, including skin. The texture of the skin decreases with age i.e. structural and physiologic transformation that arise as a natural result of intrinsic aging in addition with the effects of a lifetime of on-going cumulative extrinsic damage and environment insult (e.g. overexposure to solar irradiation) can produce a marked vulnerability to dermatologic disorders in the elderly ${ }^{2}$. Geriatric health care has absorbed a worldwide attention, but few statistical studies were carried out about skin diseases in this age group. 30 years ago, the American HANES survey demonstrated that the frequency of skin disorders increases with age so that at the age of 70 some $70 \%$ had a significant skin condition and many others had multiple skin problems ${ }^{3}$. The integrity of the skin declines with age i.e. structural and physiologic changes that occur as a natural consequence of intrinsic aging combined with the effects of a lifetime of ongoing cumulative extrinsic damage and environment insult (e.g. overexposure to solar irradiation) can produce a marked susceptibility to dermatologic disorders in the elderly ${ }^{4}$. Neurological and/or systemic diseases, health and hygiene, socioeconomic status, climate, color of skin, gender, nutrition, culture, and personal habits, such as smoking or drinking, etc., may also contribute a role in the genesis of cutaneous conditions in the elderly population ${ }^{5}$, such as xerosis, 
fungal infections, psoriasis, scabies, dermatitis, photosensitivity, purpura, uneven pigmentation, comedones $^{6}$. Demographic aging is now well established. Thus, skin diseases in the elderly will continue to become an increasingly important public health issue ${ }^{7}$.

\section{Materials and Methods}

This was a cross-sectional observational study and non-probability convenient sampling technique was used. Patients were recruited from attending the Dermatology Out-patient Department of SZMCH during the study from January'2018 to July'2018. Patients included in the study had skin diseases aged between 60-80 years, including all those who were diabetic and hypertensive because diabetes and hypertension are the most common comorbid conditions. Patients were included having skin infections including pruritus, dermatitis, xerosis, eczema, psoriasis, scabies, bacterial infection, fungal infections. Patients who were unwilling and having any systemic disease such as chronic liver disease, thyroid dysfunction, parkinson's disease, stroke and chronic renal failure were excluded on the basis of history, examination and previous investigations. Patients aged 60 years and above belonging to either sex with skin diseases presenting in outpatient department were included in this study. Diagnosis of cutaneous diseases was made on history and clinical examination. Any cutaneous diseases with onset before 60 years of age were excluded on the basis of history, examination and previous investigations. The questionnaire included data on the demographic profile, type of skin diseases and cause of skin diseases, age, gender, occupational and socioeconomic status. Data was entered and all analysis was conducted on SPSS (Statistical Package for Social Sciences) Version 20. Descriptive statistics were calculated for continuous variables of age with mean $\pm \mathrm{SD}$. For categorical variables frequency and percentages were calculated. Data was presented in tables. Chi square was used to compare age and gender with skin diseases, p-value $<0.05$ was considered statistically significant.

\section{Results}

More than half $(53.0 \%)$ patients belonged to age $71-80$ years. The mean age was found $68.5 \pm 7.0$ years with range from 61 to 82 years. Majority $(58.0 \%)$ patients were male and $42(42.0 \%)$ patients were female. Male female ratio was 1.4:1. Almost two third (61.0\%) patients were from rural area and $39(39.0 \%)$ were of urban area (Table I). Three fourth $(75.0 \%)$ patients had pruritus followed by $37(37.0 \%)$ had dermatitis, 24(24.0\%) had xerosis, 23(23.0\%) had eczema and $12(12.0 \%$ ) had bacterial infections (Table II). Pruritus, dermatitis, eczema and bacterial infections were statistically significant $(\mathrm{p}<0.05)$ among three groups (Table III).
Table-I: Demographic profile of the study population $(n=100)$.

\begin{tabular}{lcc}
\hline & Number of patients & Percentage \\
\hline Age (year) & 36 & 36.0 \\
$61-70$ & 53 & 53.0 \\
$71-80$ & 11 & 11.0 \\
$>80$ & \multicolumn{2}{c}{$68.5 \pm 7.0$} \\
\hline Mean \pm SD & \multicolumn{2}{c}{$61-82$} \\
Range & & 58.0 \\
Sex & 58 & 42.0 \\
$\quad$ Male & 42 & 61.0 \\
$\quad$ Female & & 39.0 \\
\hline Residence & 61 & \\
$\quad$ Rural & 39 & Urban
\end{tabular}

Table-II: Skin diseases of the study population $(n=100)$.

\begin{tabular}{lcc}
\hline Skin diseases & $\begin{array}{c}\text { Number of } \\
\text { patients }\end{array}$ & Percentage \\
\hline Pruritus & 75 & 75.0 \\
Dermatitis & 37 & 37.0 \\
Xerosis & 24 & 24.0 \\
Eczema & 23 & 23.0 \\
Bacterial infections & 12 & 12.0 \\
Fungal infections & 10 & 10.0 \\
Psoriasis & 7 & 7.0 \\
Scabies & 6 & 6.0 \\
Skin cancer & 4 & 4.0 \\
\hline
\end{tabular}

Table-III: Association between skin diseases with age $(n=100)$.

\begin{tabular}{|c|c|c|c|c|c|c|c|}
\hline \multirow[t]{2}{*}{ Skin diseases } & \multicolumn{2}{|c|}{$\begin{array}{c}\text { Age } 61-70 \\
\text { years } \\
(\mathrm{n}=36)\end{array}$} & \multicolumn{2}{|c|}{$\begin{array}{c}\text { Age } 71-80 \\
\text { years } \\
(\mathrm{n}=53)\end{array}$} & \multicolumn{2}{|c|}{$\begin{array}{c}\text { Age }>80 \\
\text { years } \\
(n=11)\end{array}$} & \multirow[t]{2}{*}{$\overline{p \text { value }}$} \\
\hline & $n$ & $\%$ & $\mathrm{n}$ & $\%$ & $n$ & $\%$ & \\
\hline Pruritus & 30 & 83.3 & 41 & 77.4 & 4 & 36.4 & $0.006^{\mathrm{s}}$ \\
\hline Dermatitis & 17 & 47.2 & 12 & 22.6 & 8 & 72.7 & $0.002^{\mathrm{s}}$ \\
\hline Xerosis & 9 & 25.0 & 12 & 22.6 & 3 & 27.3 & $0.933^{\mathrm{ns}}$ \\
\hline Eczema & 14 & 38.9 & 9 & 17.0 & 0 & 0.0 & $0.009^{\mathrm{s}}$ \\
\hline Bacterial & 9 & 25.0 & 3 & 5.7 & 0 & 0.0 & $0.010^{\mathrm{s}}$ \\
\hline Fungal infections & 6 & 16.7 & 4 & 7.5 & 0 & 0.0 & $0.187^{\mathrm{ns}}$ \\
\hline Psoriasis & 3 & 8.3 & 2 & 3.8 & 2 & 18.2 & $0.217^{\mathrm{ns}}$ \\
\hline Scabies & 2 & 5.6 & 3 & 5.7 & 1 & 9.1 & $0.900^{\mathrm{ns}}$ \\
\hline Skin cancer & 1 & 2.8 & 2 & 3.8 & 1 & 9.1 & $0.641^{\mathrm{ns}}$ \\
\hline
\end{tabular}

$\mathrm{s}=$ significant, $\mathrm{ns}=$ not significant

$\mathrm{p}$ value reached from chi square test

\section{Discussion}

In present study it is observed that more than half (53.0\%) patients belonged to age 71-80 years. The mean age was 
found $68.5 \pm 7.0$ years with range from 61 to 82 years. Majority $(58.0 \%)$ patients were male and $42(42.0 \%)$ patients were female. Male female ratio was 1.4:1. Almost two third $(61.0 \%)$ patients were rural area and 39(39.0\%) were urban area. In Kalar et $\mathrm{a}^{2}$ study found all patients with skin diseases aged between 60-65 and over 65 years. Mponda K and Masenga study observed age ranges 55-99 years, median age of 67.5 years were seen ${ }^{8}$. Reszke et al. ${ }^{1}$ study also be reported that the mean \pm standard deviation (SD) age of all participants was $76.1 \pm 6.1$ years (range:65-92 years). Whereas women (59.1\%) and 81 men $(40.9 \%)$ were examined. Chowdhury et $\mathrm{al}^{9}$ have showed the mean age of presentation was $67.7 \pm 6.08$ year. Most of the patients (61\%) belonged to age group 60-69 year followed by $33 \%$ between $70-79$ year and $6 \%$ were of 80 years and above. There were 110 males and 90 females with male: female ratio was 1.2:1.

In this study three fourth $(75.0 \%)$ patients had pruritus followed by $37(37.0 \%)$ had dermatitis, $24(24.0 \%)$ had xerosis, $23(23.0 \%)$ had eczema and $12(12.0 \%)$ had bacterial infections. In the study of Chowdhury et $\mathrm{al}^{9}$ observed that the most common presenting and associated complaint was pruritus and it was present in almost $74 \%$ of this population. Eczematous condition were the most common presenting disorder (39\%), followed by infection $(38 \%)$, pigmentary disorders in $26 \%$, papulosqamous in $18 \%$ and immunobullous disorders in $5 \%$ cases. Among the eczematous conditions asteatotic dermatitis $(20 \%)$ was most common followed by seborrheic dermatitis (15\%). Thapa et al ${ }^{10}$ where eczema (35.8\%) was most common and in Khawar et a ${ }^{11}$ eczema (40\%).was after scabies, fungal infections were dominant (13.6\%) in both age groups. Similar to Thapa et al. ${ }^{10}$ pruritus, dermatitis, eczema and bacterial infections were statistically significant $(p<0.05)$ among three groups. Kalar et al. ${ }^{2}$ shown that in the $<60$ years of age group, the frequency of diseases in decreasing order was found as follows: scabies (15.5\%), fungal infections $13.6 \%$, eczema $6.4 \%$, pruritus $5.9 \%$, bacterial infections and contact dermatitis $5.5 \%$, psoriasis $5 \%$. In the $>60$ years of age group: scabies $8.6 \%$, fungal infections $5.9 \%$, eczema and xerosis $3.6 \%$, contact dermatitis $2.6 \%$, viral infections $2.3 \%$. Darjani et a $1^{12}$ study revealed that the most frequent diseases of erythematosquamous diseases were defined as dermatitis $(16.6 \%)$, psoriasis $(12.3 \%)$, lichen planus $(5.45 \%)$ and pilaris rubra pityriasis $(1.1 \%)$. Fungal infections (tinea, candidiasis) were the most common infectious diseases $(8.2 \%)$ followed by viral infections (herpes zoster) (4.5\%) and infestations (scabies) (4.3\%). The most common precancerous lesion was actinic keratosis $(24.3 \%)$. BCC by $8.8 \%$ was the most prevalent skin carcinoma. Skin tag $(48.8 \%)$ and seborrheic keratosis $(8 \%)$ were the most common benign neoplasm and $69 \%$ of patients with skin tag were females. Pruritus was the common problem in other dermatological diseases $(22 \%)$. Pruritus in 60-69 years group 20.8\%, 70-79years group $22.9 \%$ and $\geq 80$ years $26 \%$. Dermatitis in $60-69$ years group $16 \%, 70-79$ years group $13.8 \%$ and $\geq 80$ years $28.3 \%$. Xerosis in $60-69$ years group $12 \%, 70-79$ years group $9.7 \%$ and $\geq 80$ years $15.2 \%$. Fungal infections in $60-69$ years group $8 \%, 70-79$ years group $6.9 \%$ and $\geq 80$ years $13 \%$. Psoriasis in 60-69 years group 14.4\%, 70-79 years group $9 \%$ and $\geq 80$ years $10.9 \%$ Scabies in $60-69$ years group $4 \%$, $70-79$ years group $3.5 \%$ and $\geq 80$ years $8.7 \%$.

\section{Conclusion}

More than half of the patients belonged to age more than 70 years of age. Various systemic diseases contribute to the presence in present study which were three fourth pruritus followed by more common were found dermatitis, xerosis, eczema and bacterial infection. Pruritis, dermatitis, eczema and bacterial infections were statistically significant in different age groups.

\section{Conflict of Interests: None.}

\section{Acknowledgement}

Patients who willingly participated in this study, other Professors and fellow colleagues with technical staffs of the Department of Dermatology \& Venereology of Shaheed Ziaur Rahman Medical College Hospital, Bogura along with Mr. Shamim Miah, Senior Scientific Officer, Bangladesh Medical Research Council, Mohakhali, Dhaka, Bangladesh.

\section{References}

1. Reszke R, Pełka D, Walasek A, Machaj Z, Reich A. Skin disorders in elderly subjects. International Journal of Dermatology. 2015; 54: e332-e338.

https://doi.org/10.1111/ijd.12832

PMid:26148310

2. Kalar MU, Mustafa SH, Zaidi SSF, Zuhair R, Bano M, Fatima F, et al. Skin Disorders in Elderly Population Attending Tertiary Care Hospital in Karachi. International Journal of Collaborative Research on Internal Medicine \& Public Health. 2016; 8(6): 381-88.

3. Marks R. Skin disease in the elderly. European Journal of Dermatology. 2006; 16(4): 460-461.

4. Farage MA., Miller KW., Berardesca E., Maibach HI. Clinical implications of aging skin: cutaneous disorders in the elderly. Am J Clin Dermatol. 2009; 10:73-86. https://doi.org/10.2165/00128071-200910020-00001 PMid: 19222248

5. Grover S, Narasimhalu C. A clinical study of skin changes in geriatric population. Indian $\mathrm{J}$ Dermatol Venereol Leprol. 2009; 75: 305-6.

https://doi.org/10.4103/0378-6323.51266

PMid: 19439890

6. Patange SV, Fernandez RJ. A study of geriatric dermatoses. Indian J Dermatol Venereol Leprol. 1995; 61: 206-8.

7. Saçar T, Saçar H. Prevalence of dermatosis in the geriatric population in Izmir region. Turk Geriatri Dergisi. 2011; 14(3): 231-7. 
8. Mponda K, Masenga J. Skin diseases among elderly patients attending skin clinic at the Regional Dermatology Training Centre, Northern Tanzania: a cross-sectional study. BMC Res Notes. 2016; 9: 119:2-5

https://doi.org/10.1186/s13104-016-1933-6

PMid:26905256 PMCid:PMC4763417

9. Chowdhury J, Das S, Roy AK. Skin diseases in elderly population from Eastern India- An observational study. Journal of Pakistan Association of Dermatologists. 2016; 26 (4): 318-321.

10. Thapa DP., Jha Ak., Kharel C., Shrestha S. Dermatological problems in geriatric patients: a hospital based study. Nepal Med Coll J. 2012; 14: 193-195.
11. Khurshid K., Irfanullah., Paracha MM., Amin S., Pal SS. Frequency of Cutaneous Diseases in Geriatric population of type IV and V Skin. JPMI. 2012; 1: 39-42.

12. Darjani A, Mohtasham-Amiri Z, Amini KM, Javad Golchai J, Sadre-Eshkevari S, Narges Alizade. Skin Disorders among Elder Patients in a Referral Center in Northern Iran. Dermatology Research and Practice. 2011; 1-4.

https://doi.org/10.1155/2013/193205

PMid:23935606 PMCid:PMC3722782 